\title{
CONTAÇÃO DE CONTAR HISTÓRIAS PARA ALÉM DO CONTEXTO HOSPITALAR: LIGA DA HUMANIZAÇÃO PROJETO DE EXTENSÃO BEM-ME QUER- CAPES-UFGD
}

Storytelling beyond from hospital: Humanization turns on Extension Project Bem- me- quer Capes - UFGD

DOI: $10.30612 /$ re-ufgd.v6i11.5625

Alessandra Domingos de Souza ${ }^{1}$ Cristina Gonçalves de Souza ${ }^{2}$

Recebido: 22/09/2018Ａceito: 10/04/2019

Resumo: O presente estudo surgiu no intuito de apontar que o lúdico não se refere apenas ao brincar, jogar, movimentar-se espontaneamente. O lúdico é essencial no desenvolvimento humano acrescentando ingredientes indispensáveis no relacionamento interpessoal, facilitando também a criatividade e estabelecendo relações, proporcionando a melhoria em casos clínicos. Para tanto abordaremos o relato de experiência proporcionado pelo núcleo de contação de histórias, buscaremos apresentar brevemente a importância da contação de histórias em contexto formal e não formal de ensino, para a melhoria da criança em seu aspecto integral. Sendo que o Projeto Bem-meQuer, é um projeto de extensão criado em 2007 pelo CACES- Centro Acadêmico Camilo Ermelindo da Silva-Medicina-UFGD. E que tem como meta a humanização dos serviços de atendimento da saúde pública, o projeto é composto por voluntários divididos em três núcleos: Contadores de Histórias, Palhaços e músicos, que visitam por meio de escalas (e cada qual em seu núcleo de atuação), aos finais de semana o Hospital universitário, o Lar de crianças (Santa Rita), o Pronto Atendimento Médico de Dourados e o Lar do Idoso para interagir com os pacientes e funcionários das instituições. Concluímos que o Projeto Bem-me-Quer, possui uma prática pedagógica lúdica e perpassa a realidade infantil, do adulto e idoso, fazendo o mesmo transcender de momentos de dor, "levando-o" para um contexto de alegria, facilitando o desenvolvimento pessoal, social e cultural, colaborando para a boa saúde mental e física.

Palavras-Chave: Saúde Coletiva, Voluntariado e Prática Pedagógica.

Abstract - This study appeared in order to point out that the playful refers not only to play, play, move spontaneously. The playfulness is essential in human development adding essential ingredients in interpersonal relationships, also facilitating creativity and establishing relationships, providing improvement in clinical cases. For this approach the experience report provided by the core of storytelling, seek briefly present the importance of storytelling in formal settings and nonformal education, to improve the child in its full aspect. Since the Project Bem-me-Quer, is an extension project created in 2007 per CACES- Academic Center Ermelindo Camilo da SilvaMedicine UFGD. And that aims humanization of public health care services, the project consists of

1 Faculdade de Educação da Universidade Federal da Grande Dourados - FAED/UFGD (alessandra1415@hotmail.com )

2 Professora de Educação Básica, Escola Maria da Conceição Angélica- Dourados (cris774@yahoo.com.br )

Souza \& Souza, p. 44-54 
volunteers divided into three sections: Storytellers, clowns and musicians, who visit through scales (and each in its core operations), weekends the university Hospital, the Home of children (Santa Rita ), the Emergency Department Medical Dourados and the Home for the Elderly to interact with patients and staff of the institutions. we conclude that good me Want Project, has a playful teaching practice and runs through children's reality, the adult and elderly, doing the same transcend moments of pain, " taking it" to a context of joy, facilitating personal development, social and cultural, contributing to good mental and physical health.

Keywords: Collective Health, Volunteering and Teaching.

\section{Introdução}

Neste estudo buscaremos apresentar brevemente a importância da contação de histórias no contexto educacional formal e não formal, pois a contacão de histórias vem sendo apresentada e defendida por alguns autores como sendo uma prática pedagógica lúdica, que englobada no cotidiano escolar e na realidade infantil, pode contribuir significativamente para a qualidade do ensino e para o desenvolvimento integral das crianças, adultos e idosos.

A Escola tem enfrentado grandes desafios no que tange o processo de alfabetização e letramento aprender algo, de forma divertida, lúdica, por meio de jogos, dinâmicas e projetos de contação de histórias, proporciona uma maior interação entre o aluno e o aprendizado, independente da idade a ludicidade em contexto formal de ensino é importante por que propicia uma aula agradável permitindo aos alunos uma maior assimilação, propicia também o desenvolvimento de outros aspectos importantes como o desenvolvimento da cognição, ou seja do raciocínio, pois na brincadeira, o indivíduo .vai interpretar de uma forma mais positiva o conteúdo, ou aquilo que a professor (a), quis transmitir, o mesmo irá sentir-se mais satisfeito e envolvido, parte do contexto educacional.

Ao que se refere ao contexto não formal, abordamos um relato de experiência proporcionado pelo Projeto Bem-me-Quer, sendo que o mesmo é um projeto de extensão criado em 2007 pelo CACES - Centro Acadêmico Camilo Ermelindo da Silva - Medicina-UFGD, e que tem como meta a humanização dos serviços de atendimento da saúde pública.

O projeto é composto por voluntários acadêmicos da UFGD e UEMS, divididos em três núcleos: Contadores de Histórias, Palhaços e Músicos, que visitam aos finais de semana o Hospital Universitário, o Lar de Crianças Santa Rita, o Pronto Atendimento Médico de Dourados e o Lar do Idoso.

As visitas ocorrem com foco na interação, entre integrantes do projeto, com os pacientes e funcionários das instituições. Observa-se por meio de análise e relato de experiência 
uma melhora significativa na recuperação e proporciona esperança no tratamento dos pacientes institucionalizados, além dos benefícios nas relações e no ambiente de trabalho dos profissionais de saúde.

O projeto procura levar um atendimento de saúde humanizado, considerando todos os aspectos biopsicossociais do ser humano, neste caso abordaremos o relato de experiência proporcionado pelo núcleo de contacão de histórias, buscamos apresentar brevemente a importância da contação de histórias no contexto não formal de ensino, para a melhoria da criança em seu aspecto integral.

\section{Metodologia}

Para tanto, a pesquisa utiliza o método qualitativo que conforme Chizzotti (2001, p. 98) se constitui em "um método de tratamento e análise de informações, colhidas por meio de técnicas de coleta de dados, consubstanciadas em um documento". (CHIZZOTTI, 2001, p. 98), e tem um caráter teórico e prático, o embasamento teórico foi realizado por meio da pesquisa bibliográfica, no qual foram analisados, capítulos de livros e artigos em periódicos.

A parte prática deste trabalho consiste em relatos de experiências, na qual foram trabalhados em sala de aula e em contextos não formais de ensino, projetos de contação de histórias mediados por uma discente do curso de Pedagogia e por uma Psicopedagoga durante o ano letivo de $2014 / 2015$.

Relacionamos a prática observada aos resultados da pesquisa bibliográfica, concluímos que a contação de histórias é um mecanismo lúdico, facilitador e ampliador de práticas pedagógicas no processo educacional e para o desenvolvimento integral do ser humano.

\section{Resultados e discussão - A importância da ludicidade}

O lúdico não se refere apenas ao brincar, jogar, movimentar-se espontaneamente, o lúdico é essencial no desenvolvimento humano acrescentando ingredientes indispensáveis no relacionamento interpessoal, facilitando também a criatividade e estabelecendo relações com o outro e com o mundo.

Sendo que a contação de histórias é um mecanismo lúdico, facilitador e ampliador de práticas pedagógicas no processo educacional. As manifestações lúdicas desempenham funções muito importantes no desenvolvimento das crianças e podem ser utilizadas como uma importante ferramenta metodológica da prática docente. 
Conforme Barbosa (2007) são poucos os documentos que falam sobre a imaginação

infantil e sua importância para o desenvolvimento da mesma, no entanto podemos destacar a Lei de Diretrizes e Bases da Educação (2010) pois a mesma aponta para o desenvolvimento integral da criança:

Art. 29 A educação infantil, primeira etapa da educação básica, tem com finalidade o desenvolvimento integral da criança até os seis anos de idade, em seus aspectos físico, psicológico, intelectual e social, complementando a ação da família e da comunidade.

Art. 30 A educação infantil será oferecida em: I - creches ou entidades equivalentes, para crianças de até três anos de idade; II - pré - escolas para crianças de quatro a seis anos de idade.

Art. $31 \mathrm{Na}$ educação infantil a avaliação far-se-á mediante acompanhamento e registro de seu desenvolvimento, sem o objetivo de promoção, mesmo para o acesso ao ensino fundamental. (Brasil, 1996).

Nesse sentido a Contação de histórias vem se mostrando de suma importância no contexto educacional uma vez que possibilita maior socialização e interação entre aluno/aluno e professor/aluno, oportunizando para as crianças o gosto pela aprendizagem, fazendo-a viver aquele momento como se fosse realidade, ou seja, proporcionando para a criança um desenvolvimento integral, sendo que para Vygotsky (1987), a "aprendizagem e o desenvolvimento estão estritamente relacionados", acredita-se que um passo importante para desenvolver as habilidades necessárias, além do trabalho lúdico é acreditar no trabalho desenvolvido pela criança, valorizar a capacidade de cada um de criar, recriar e de imaginar.

Para tanto os professores exercem grande influência na vida de seus alunos, são os responsáveis pela mediação e de tal forma contribuem para que a aprendizagem ocorra de forma eficiente, respeitando o tempo e a realidade de cada criança, pois conforme revisão de literatura; Postic (1993); Radino (2003); Ribeiro (1999); Fritzen (2007); Morais (1996); Oliveira (1997); Bamberger (1995); Coelho (2001); Villardi (1997), aprender algo, de forma descontraída seja ouvindo ou encenando uma história, proporciona uma maior interação entre o estudante e o aprendizado, a importância da ludicidade propicia uma aula agradável permitindo aos alunos uma maior assimilação, a ludicidade propicia também o desenvolvimento de outros aspectos importantes como o desenvolvimento do raciocínio da criança, na brincadeira, a criança vai interpretar de uma forma mais positiva o conteúdo, ou aquilo que a professor (a), quis passar para o aluno, irá sentir-se mais satisfeito e envolvido, parte do contexto educacional.

Piaget (1976, p. 160) diz que a atividade lúdica é o "berço obrigatório das atividades 
intelectuais da criança, uma assimilação do real à realidade própria", fornecendo a este seu alimento necessário e transformando o real em função das necessidades múltiplas do eu.

É importante que o lúdico enquanto recurso pedagógico seja encarado de forma séria, responsável e com objetivos claros do que se pretende alcançar, aonde desejamos chegar com o mesmo, favorecendo de forma eficiente o desenvolvimento pleno e contemplando todas as potencialidades da criança.

Educar é a peça chave deste processo, devendo ser encarada como um elemento essencial e fundamental educar não se limita apenas em repassar informações e conhecimentos, mas ajudar a pessoa a tomar consciência de si mesma, dos outros e da sociedade.

É oferecer várias ferramentas para que a pessoa possa escolher entre muitos caminhos, aquele que for compatível com seus valores, sua visão de mundo e com circunstâncias adversas que cada um irá encontrar.

\section{Atividades desenvolvidas em Contexto Formal}

Para tanto apresento-lhes brevemente algumas fotos, de atividades desenvolvidas em contexto formal de ensino, para que possam assimilar o embasamento teórico abordado, com a prática pedagógica, com o espeço escolar, e principalmente com a realidade das crianças.

A primeira e a segunda imagem dizem respeito, a leitura livre na biblioteca, o foco foi promover a interação das crianças com o espaço, com os livros e com os outros. Os alunos foram direcionados a biblioteca para irem se familiarizando com as diversas obras existentes.

Tornando possível expandir o conhecimento da turma e ampliar os horizontes dos alunos, que sentirão necessidade de acessar outras fontes e estações, como bibliotecas públicas, para isso ao chegarem na biblioteca, houve uma conversa introdutória sobre a importância das bibliotecas públicas para tornar acessível a comunidade, o conhecimento historicamente produzido. 
Figura 1: Leitura livre na biblioteca/ Promovendo a Interação e a Socialização.

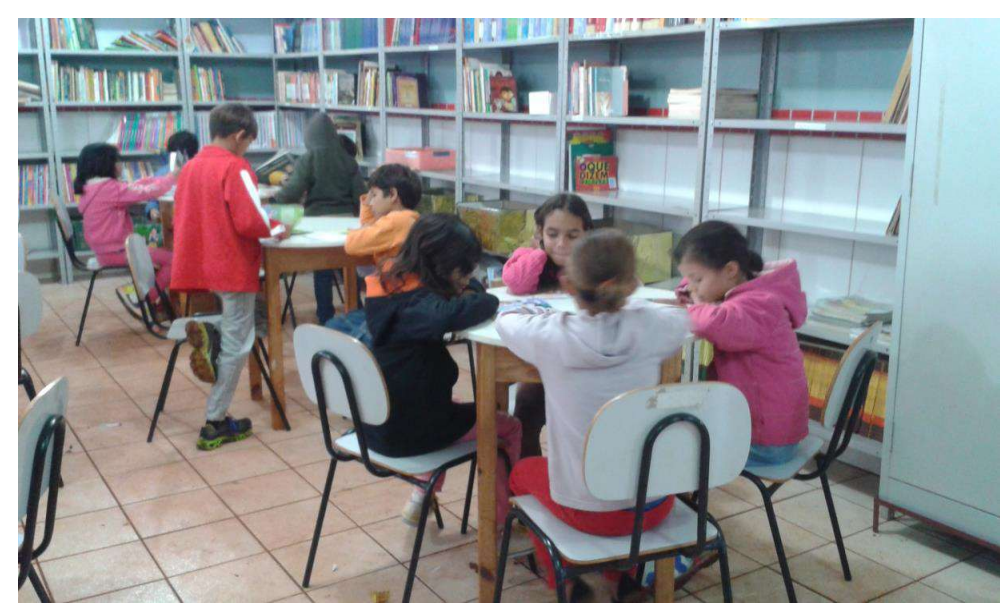

Buscamos também, estimular a autonomia das crianças, pois os livros não foram impostos, os mesmos escolheram os livros que lhe agradavam, e se sentaram aonde se sentiram mais confortáveis, tiveram acesso as mais variadas obras e foram instigados a se apropriarem das bibliotecas públicas, tendo em vista que

[...] os diversos segmentos da sociedade têm expectativas diferentes em relação ao papel da biblioteca pública. A indústria editorial acredita que o objetivo fundamental é a formação de um público leitor. Os educadores acreditam que a biblioteca deve ser o alicerce do processo ensino aprendizagem. Os intelectuais acreditam que deve ser um espaço rico em literatura de ficção. O trabalhador comum não vê a biblioteca como um local para solucionar os problemas do cotidiano (SUAIDEN, 2000, p. 57).

Mas de acordo com Bernardino e Suaiden (2011, p. 36), a "Biblioteca Pública é uma instituição que abriga em seu escopo a máxima de acesso à informação a todos sem distinção", é o lugar social de transmissão de conhecimento. Essa dinâmica é fator fundamental na sociedade atual, em que há diversas informações em redes sociais e televisivas, rádios que necessitam de um olhar crítico e cientifico, que pode ser obtido e analisado em instancias conceituadas de transmissão do saber, como no caso a biblioteca escolar e pública, estimular as crianças a se apropriarem deste espaço, fazendo as perceber nessa instituição um ambiente, estimulador e aconchegante e dar contribuir para a construção de uma sociedade mais justa e igualitária, crítica e reflexiva. 
Figura 2: Leitura livre em ambiente lúdico, estimulador e aconchegante

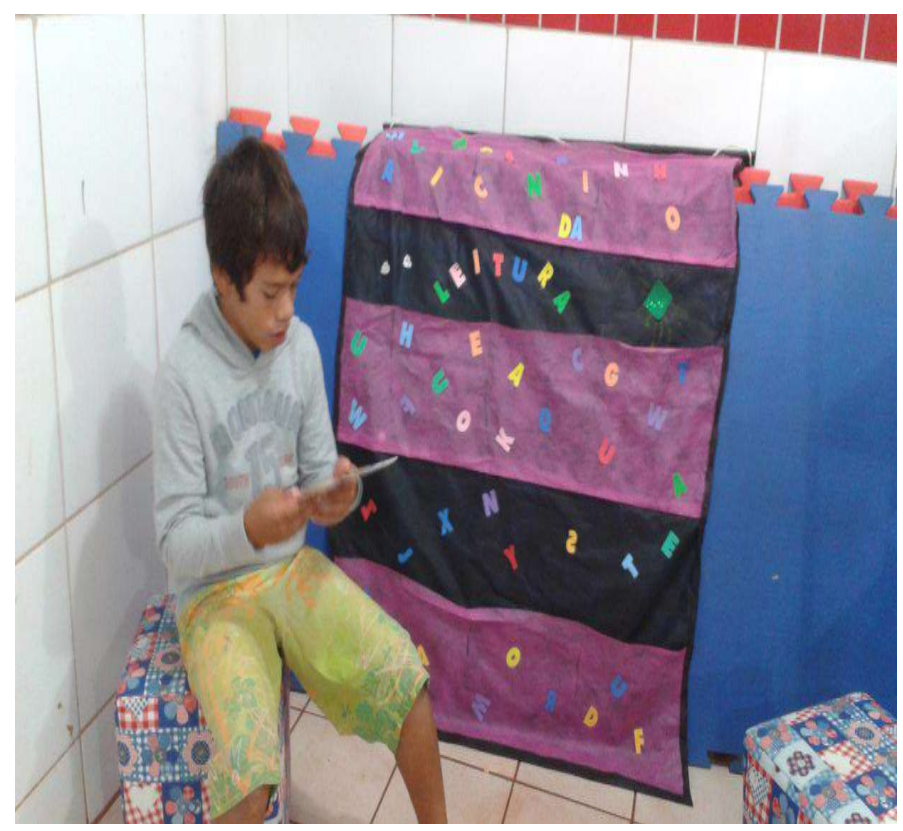

Fornecer as crianças autonomia é ampliar as possibilidades de criação da mesma e pensando em criação e diversidade, a terceira foto aborda a questão da apreciação musical que é de suma importância no processo corrente de ensino- aprendizagem durante a educação básica e educação infantil. Para tanto utilizamos da musicalização para contar e recontar histórias, como também possibilitamos as crianças este momento de criação, interação e autonomia, para pegar no objeto no caso o violão e se expressar livremente.

Figura 3: Contação de História por meio da Musicalização

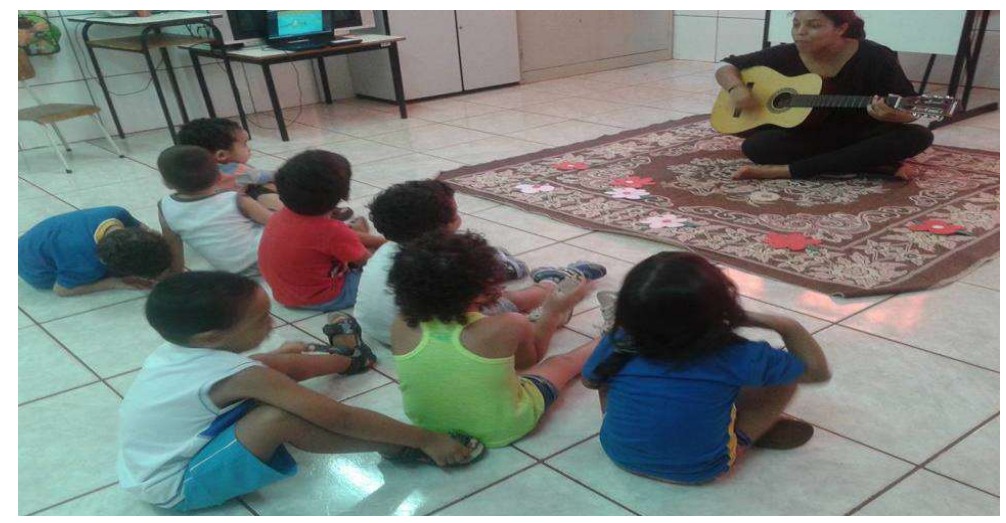

Atividades desenvolvidas em Contexto Não Formal 
A educação não formal pode desenvolver-se em variados espaços e para que ela ocorra de forma qualitativa é necessário a participação da sociedade civil, seja como atuante ou como beneficiário. O Projeto Bem-me-quer-Capes/UFGD, iniciou-se com a atuação em hospitais, porém o projeto assumiu tamanha proporção que é convidado a participar de diversas ações sociais, incluindo fora da cidade de Dourados.

Figura 4: Ação social Bem-me-quer/ Dourados-MS.

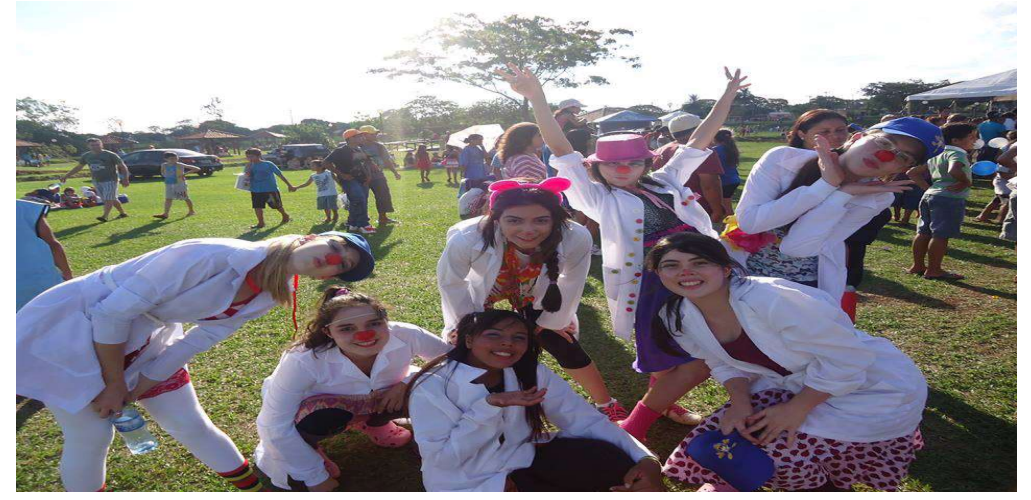

A maior importância da educação não-formal está na possibilidade de criação de novos conhecimentos, ou seja, a criatividade humana passa pela educação não-formal. A educação não-formal existe intencionalidade de dados sujeitos, em criar ou buscar determinadas qualidades e/ ou objetivos. No caso do Bem-me-quer, busca a transcendência do sujeito, afim de que por meio da alegria ele possa esquecer seus problemas, sua dor.

Figura 5: Contacão de História no HU-UFGD

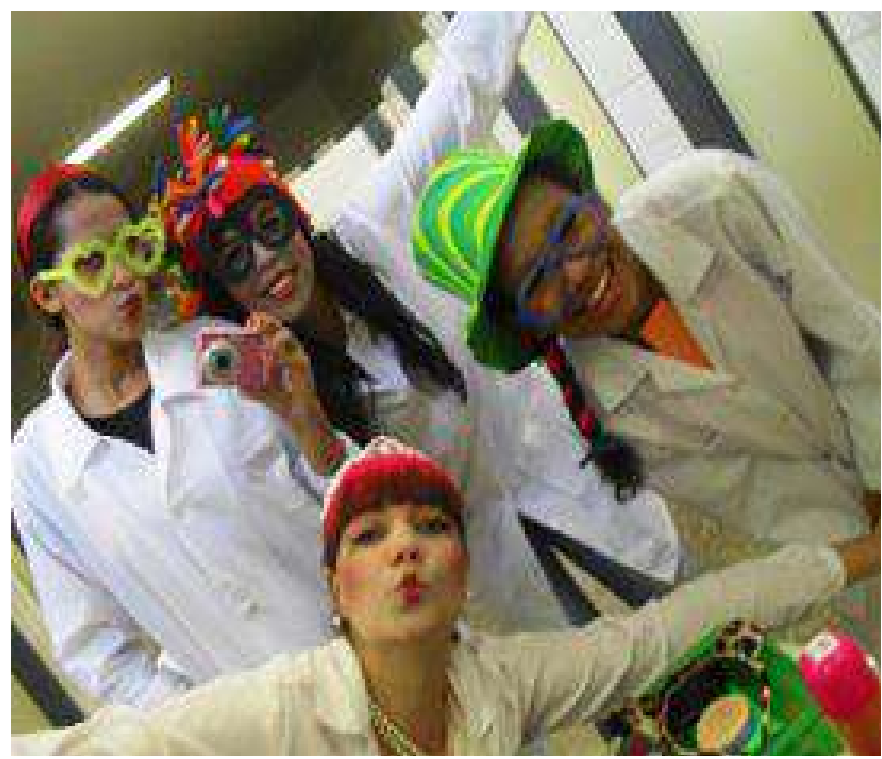


A educação não formal, abordado pelo projeto Bem-me-quer, caracteriza-se por não ser intencional ou organizada, mas casual e empírica, exercida a partir das vivências, de modo espontâneo. Por mais que existe uma organização, oficinas obrigatórias, preparação psicológica e um planejamento da visita, escalas determinadas, a atuação depende da demanda do sujeito na hora da visita.

Figura 6: Imaginando a história das nuvens "Elas são os algodão doce, que os gigantes criaram”

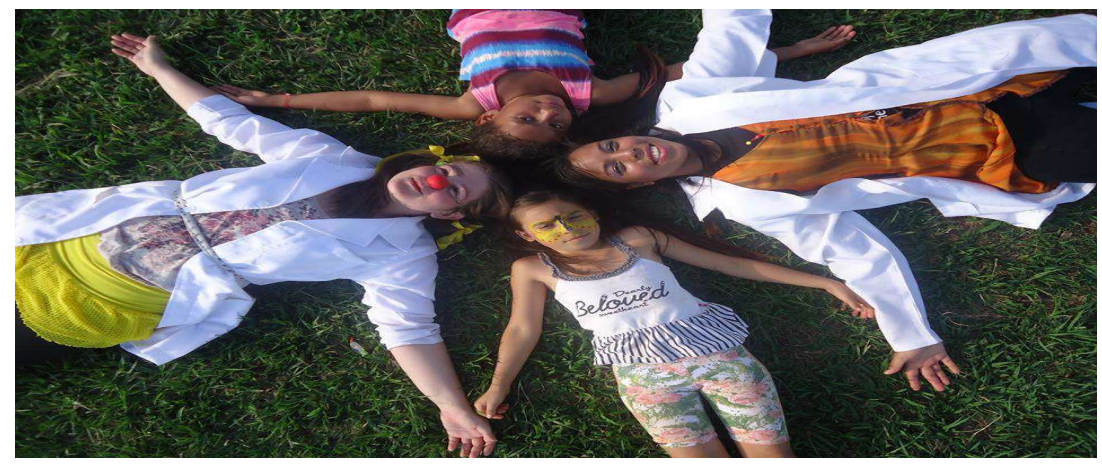

A ludicidade é uma necessidade do ser humano em qualquer idade e não pode ser vista apenas como diversão. O desenvolvimento do aspecto lúdico facilita à aprendizagem, do desenvolvimento pessoal, social e cultural colaborando para a boa saúde mental e física.

Figura 7: "Pescando sonhos".

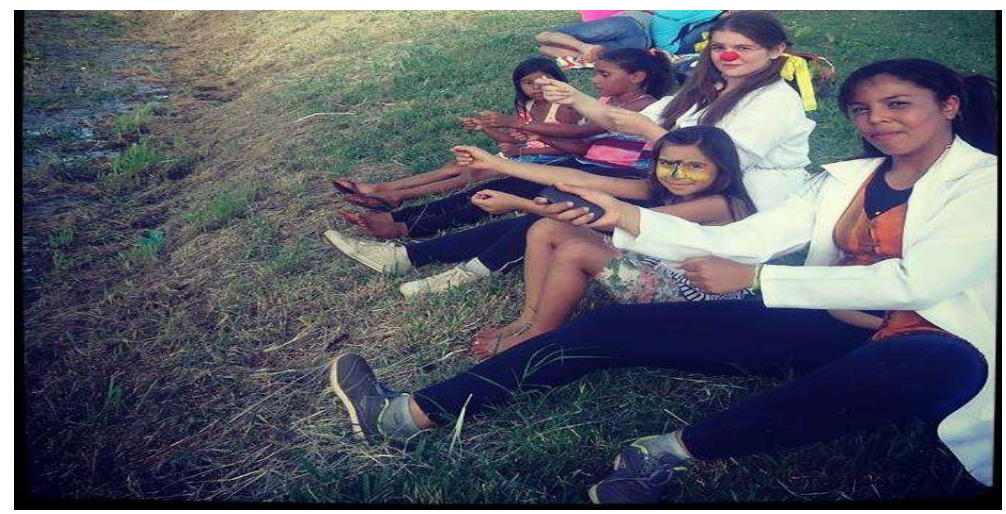

\section{Considerações Finais}

Concluímos que a contação de histórias é um mecanismo lúdico, facilitador e ampliador de práticas pedagógicas no processo educacional e que contribui significantemente para o desenvolvimento integral da criança inclusive em espaços não formais de ensino.

A ludicidade é uma necessidade do ser humano em qualquer idade e não pode ser 
vista apenas como diversão. O desenvolvimento do aspecto lúdico facilita à aprendizagem, do desenvolvimento pessoal, social e cultural colaborando para a boa saúde mental e física.

Na perspectiva de Vygotsky, a criança, inserida no social é produto de um contexto cultural. Isso facilita a exploração da imaginação, a memória e o registro e de suas experiências. Educar não se limita apenas em repassar informações e conhecimentos, mas ajudar a pessoa a tomar consciência de si mesma, dos outros e da sociedade, do conhecimento historicamente produzido.

A entrada da criança no mundo do faz-de-conta marca uma nova fase de sua capacidade de lidar com a realidade. O pensamento da criança evolui a partir de suas ações, razão pelas quais as atividades são tão importantes para o desenvolvimento do pensamento infantil.

A criança precisa de estabilidade emocional para se desenvolver com a aprendizagem. A contacão de histórias pode ser uma maneira de se chegar perto do sujeito e da ludicidade, em conjunto com um caminho estimulador e enriquecedor para se atingir uma totalidade no processo de aprender, e aprender brincando.

\section{Referências}

BAMBERGER, Richard. Como incentivar o hábito de leitura. São Paulo: Abril, 1995

BARBOSA, Maria Carmen Silveira. Legislação e propostas curriculares: há lugar para a imaginação. In: FRITZEN, Celdon; CABRAL, Gladir da Silva (Org.). Infância: imaginação e educação em debate. Campinas: Papirus, 2007. cap. 7, p. 121-139.

BERNARDINO, Maria Cleide Rodrigues; SUAIDEN, Emir Jose. O papel social da biblioteca pública na interação entre informação e conhecimento no contexto da ciência da informação. Perspectivas em Ciência da Informação, Belo Horizonte, v. 16, n. 4, out./dez. 2011. Disponível em: Acesso em: 22 Set. 2016.

BRASIL. Lei de Diretrizes e Bases da Educação Nacional. Lei 9394, de 20 de dezembro de1996. Disponível em: Acesso em: 5 Maio. 2016.

COELHO, Beth. Contar histórias: uma arte sem idade. São Paulo: Ática, 2001.

CHIZZOTTI, Antônio. Pesquisa em ciências humanas e sociais. 5.ed. São Paulo: Cortez, 2001. (Biblioteca da educação. Série 1. Escola; v.16).

FRITZEN, Celdon. Cabral, Gladir da Silva (orgs.). Infância: Imaginação e Educação em Debate. Campinas, SP: Papirus, 2007.

MORAIS, José. A arte de ler. São Paulo: UESP, 1996.

OLIVEIRA, Zilma de M. Ramos (Org.), A Criança e seu desenvolvimento: Perspectivas para se 


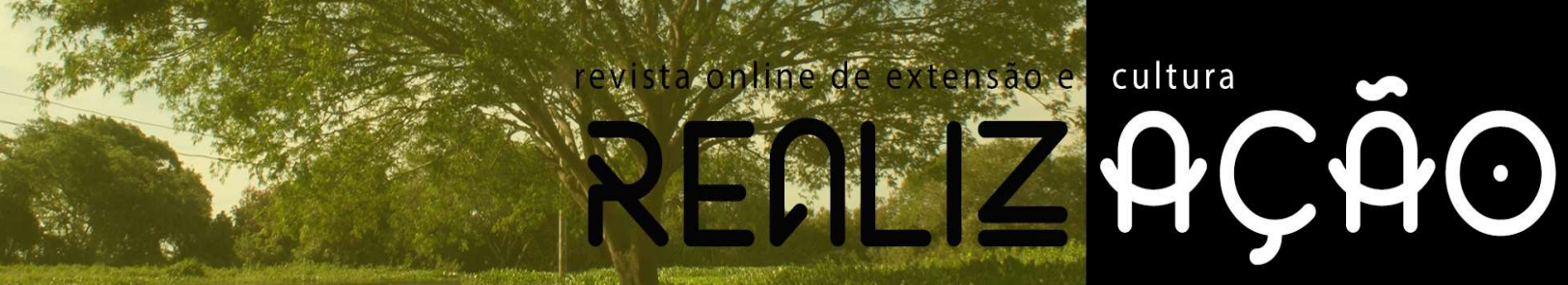

Discutir a Educação Infantil, 2a Edição. São Paulo: Cortez, 1997.

PIAGET, Jean. A formação de símbolo na Criança: Imitação, jogo, imagem e representação.

Tradução de Álvaro Cabral e Cristiane Oiticia. Rio de Jnaeiro, Zahar, 1976.

POSTIC, Marcel. O imaginário na relação pedagógica. Rio de Janeiro: Jorge Zahar, 1993.

PROJETO BEM-ME-QUER-UFGD. Núcleo de Contacão de Histórias. Promovendo Saúde através da Solidariedade - CACES 2015.

RADINO, Glória. Contos de fadas e realidade psíquica: a importância da fantasia no desenvolvimento. São Paulo: casa do Psicólogo, 2003.

RIBEIRO, Jonas. Ouvidos dourados: arte de ouvir histórias para depois contá-las. São Paulo: Ed. Ave Maria, 1999.

SUAIDEN, E. J. A biblioteca pública no contexto da sociedade da informação. Ci. Inf., Brasília, v. 29, n. 2, p. 52-60, maio/ago. 2000. Disponível em: <www.scielo.br/pdf/ci/v29n2/a07v29n2.pdf >. Acesso em: 22 set. 2016.

VILLARDI, Raquel. Ensinando a gostar de ler: formando leitores para a vida inteira. Rio de Janeiro: Qualitymark, 1997.

VYGOTSKY, Lev, Aprendizagem e desenvolvimento: um processo sóciohistórico. São Paulo: Scipione, 1997. 